\title{
The Study on Intangible Culture Heritage Protection Method by Utilizing China's University Libraries
}

\author{
An-ding LIU ${ }^{1, a}$, Xiao-jing FANG ${ }^{2, b}$, Hong-guang $\mathrm{YE}^{2, \mathrm{c}}$ \\ and $\operatorname{Bin} \mathrm{LI}^{2, \mathrm{~d},{ }^{*}}$ \\ ${ }^{1}$ Library, Wuhan Textile University, Wuhan, 430073, China \\ ${ }^{2}$ College of Fashion, Wuhan Textile University, Wuhan, 430073, China \\ aada20040705@163.com, b3453981354@qq.com, '836001463@qq.com, \\ libin790121@qq.com
}

Keywords: University Library, Intangible cultural heritage, Protection method.

\begin{abstract}
The main method for China's university libraries takes part in the protection of intangible culture heritage. It can be divided into three categories, which are basic service, publicity service, and participation in research projects. Firstly, the basic service is constituted by the university library's paper documents as well as its network protection platform; it is the minimum requirement for university's participation in intangible culture heritage protection. Secondly, the publicity service for intangible culture heritage via both online and offline methods provides a wider space for inheritance and development work, expands people's cognition and identification degree for intangible culture heritage, and also raised national self-confidence. Thirdly, the participation in research projects elevates the university library's protection level for the intangible culture heritage.
\end{abstract}

\section{Introduction}

Differences in development goals, discipline characteristics, talent composition and other factors will inevitably lead to differences in the resources of China's university library. Thus, the protection scheme of each university library in protecting intangible cultural heritage may differ as well. Based on the results from previous studies, this paper has divided the main protection methods for intangible culture heritage into three categories by using system theory, which are basic services, publicity services, and the participation in research projects.

\section{Discussions and Analyses}

Basic Service is the Minimum Requirement for China's University Libraries to Participate in the Intangible Culture Heritage Protection

Provide Literature Documents of the Intangible Cultural Heritage Research. The most basic way for university libraries to participate in the protection work is to collect and classify the mass data for different kinds of paper documents on intangible culture heritage, providing necessary information consultant for library users. However, the intangible culture heritage in China is so plentiful that the list of typical intangible cultural heritage includes 1372 national level and 464 extension items by the year 2014, and the list for province (autonomous region) level representatives contains huge quantities as well, thus, university libraries usually collect the literature documents of the intangible cultural heritage based on its location and discipline characteristics. For 
example, the library of Anqing Normal University (anqing shifan daxue) ordered a large number of literature and books about Huangmei opera research and actively collected all the valuable documents which are related to Hangmen opera from the community [1], while the library of South-Central University for Nationalities (zhongnan minzu daxue) focus on Nvshu culture, ethnologist and ancient documents when collecting the information of intangible culture heritage [2].

However, collecting literature documents is only the minimum requirement for university libraries to participate in the protection work of intangible cultural heritage. Since all these documents involves various disciplines, in order to better serve the teachers and students, universities like Donghua University and Wuhan Textile University have set special bookshelves in intensive-library or study-room only for intangible cultural heritage documents to avoid the low-usage caused by dispersive placement. Besides, university libraries also positively recruit and build volunteer organization in campus to conduct the necessary research based on the existential condition, technical process and myths and legends about local intangible culture heritage. For instance, the library of Jishou University collected numerous original documents from "field" by participating in the field survey activities held by its school of history and culture and school of arts;taking advantage of the university's ethnic culture research base of seven nationalities including the Miao, Tujia, Dong, etc[3]. These methods are worth following for all the other university libraries.

Construct Network Protection Platform for the Intangible Cultural Heritage. Constructing network protection platform for intangible cultural heritage may break the limitation in terms of time, space and objects as compared to conventional platforms, which will increase the usage and distribution of the intangible culture heritage resource. Based on previous studies and author's experience, the network protection platform can be established through the following steps (Figure 1). First, gradually build and improve the electronic databases, in order to achieve interactive publicity through the digital library and mobile library. The so-called "digital library and mobile library" is the use of digital technology and modern communication technology to digitize the intangible cultural heritage related resources, creating a vivid virtual learning and research platform by connecting the library's special subject website and feature database with the computers and mobile devices of both on- and off-campus users. Second, set up an interaction mechanism between the database users and the university librarians, continuously improving the intangible culture heritage resource in the database. In fact, users of the database include novice scholars and researchers with a mutual transformation relationship between them. When the novice scholars have learnt considerable amount of knowledge about the intangible cultural heritage, they are likely to change their role from novice scholars to a more advanced researcher. Similarly, when the researchers start a new intangible culture heritage research direction, their role will gradually revert to a novice scholar as well. In sum, users access to the university library's intangible cultural heritage database through network channel to get all the related text, audio, video and other electronic resources, while university librarians can get feedback views and suggestions to improve the network channel by the process when users using the database resource, which consequently composed a positive cycle. 


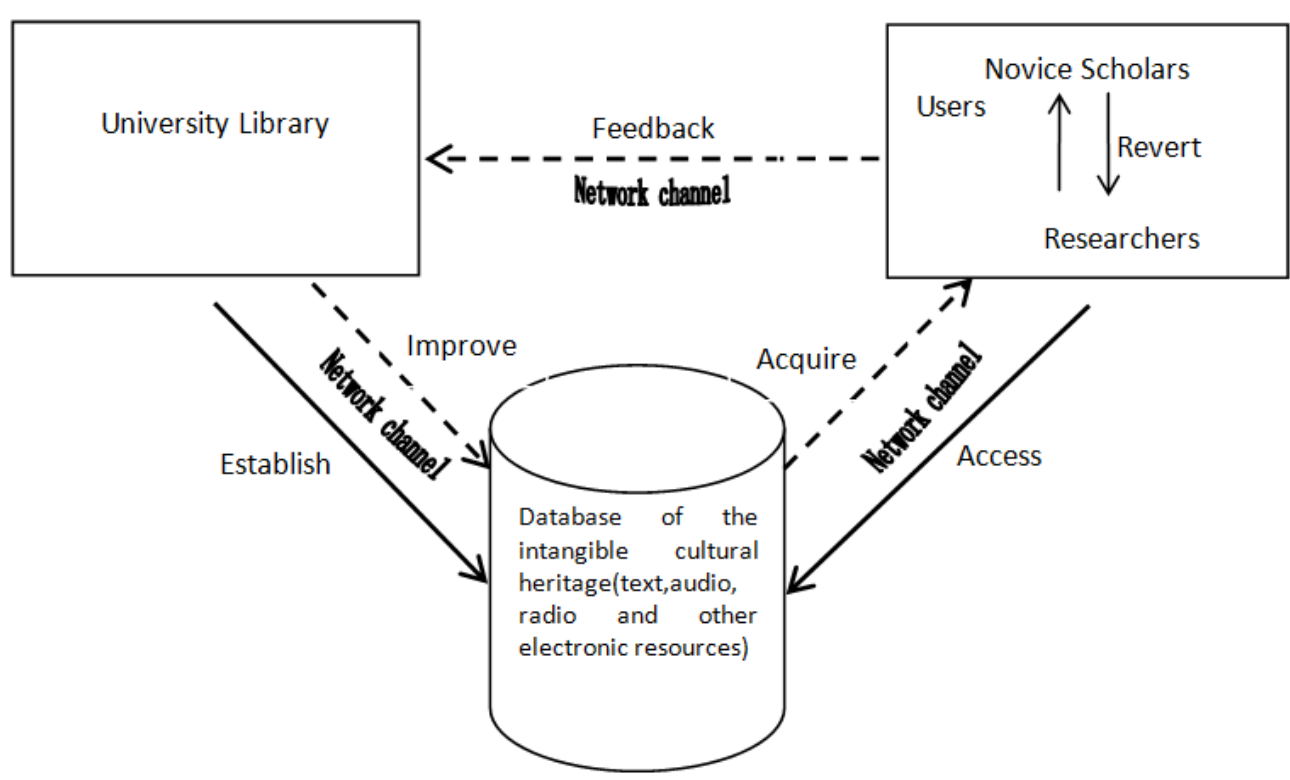

Figure 1. Procedure chart about constructing a protection platform for the intangible cultural heritage based on network environment

\section{Publicity Service has Expanded the Audience of Intangible Cultural Heritage Protection}

Publicity service is an important method for the protection of intangible cultural heritage, it provides a wider space for the inheritance and development work, expands people's cognition and identification degree, and raised national self-confidence at the same time. The UNESCO has pointed out in Convention for the Safeguarding of the Intangible Cultural Heritage that the content of intangible cultural heritage includes: (1)Oral traditions and forms of expression (2) the performing arts; (3) the social practice, etiquette, festival activities; (4)knowledge and practice about nature and the universe; (5) the traditional arts and crafts. Therefore, the university library should carry out the publicity of intangible cultural heritage from these five aspects, carrying forward excellent traditional culture as well as the national ideology and spirit. In order to make the publicity work more operable and easier to achieve, university libraries should select one certain category or one item of the intangible culture heritage as the highlight for publicity based on their heritage areas and situation. According to statistics, the intangible culture heritage includes 61 items and 35 extension ones on the nation basis, in total 96 items presently in Hubei province. The national intangible cultural heritage of Hubei province covers ten categories which are folk literature, folk music, folk dance, traditional opera, ballads and art, acrobatics and athletics, folk art, traditional handicrafts, traditional medicine and folk custom. Hence, university libraries in Hubei province have abundant resources for publicity. For example, the library of Wuhan Textile University selects the Huangmei stitch (huang mei tiao hua), Han embroidery (han xiu), Hong'an embroidery (hong an xiu huo) and Yangxin cloth paste (yang xin bu tie)from the national intangible culture heritage items of dyeing and weaving class in Hubei province as the publicity highlight. This will not only play a role in inheriting the traditional culture, but also reflects the university's running characteristics of textile and garment. However, some universities where their located area does not have rich heritage resources or some of their running characteristics are not associated to intangible culture heritage, they will find it difficult when choosing the protection object for publicity. In fact, except for national level, the various provincial and 
municipal heritage projects or even the projects being authorized can all be considered as an option, and cross-regional heritage projects that related to the universities special subjects can also be regarded as the object for publicity so as to highlight the characteristics of university discipline. In summary, all university libraries can find their own breakthrough point in the protection of intangible cultural heritage, in view of their respective characteristics.

The specific publicity work will be conducted after selecting the protection project, and the approach can be mainly divided into two types: static and interactive. Firstly, the university library should select the suitable intangible cultural heritage projects according to its university characteristics and key disciplines and transform these projects into illustrated pictures or text to display in the exhibition hall, publicity column or halls of the library. In this way, they will cultivate the teachers and students' awareness to participate in the cultural heritage preservation. Secondly, university libraries can use lectures, forums, exhibitions, books, knowledge contests, reading activities and other formats to publicize and promote the knowledge of protection for intangible cultural heritage [3]. Thirdly, universities can introduce related situation of intangible cultural heritage for users outside the campus via the library website, and also connecting to the current relevant news and comments to strengthen the display effect [4]. Finally, they can set up email, QQ, WeChat and other communication methods to form the mechanism of interaction and stimulate the enthusiasm of both on- and off-campus users, providing a vast space, diversified forms and better publicity effects for preserve and carry forward the intangible cultural heritage.

\section{The Participation in Research Projects Elevates the University Library's Protection Level for the Intangible Culture Heritage}

The essence of the active participation in the intangible cultural heritage project is an important way for university libraries to extend its service and achieve the construction of research library. The extended service includes not only the extension of the service object, but also the service mode and service content, while the so-called research library is a library which can provide detailed research literature for a particular subject area [5]. Besides, the transformation for extension service and research library requires the university librarian to have the professional background of library science as well as the professional knowledge related to the expansion service content. The participation hierarchy for university libraries take part in the protection of intangible culture heritage includes three levels: basic service level, expanded service level and dominant research level (Figure 2). 


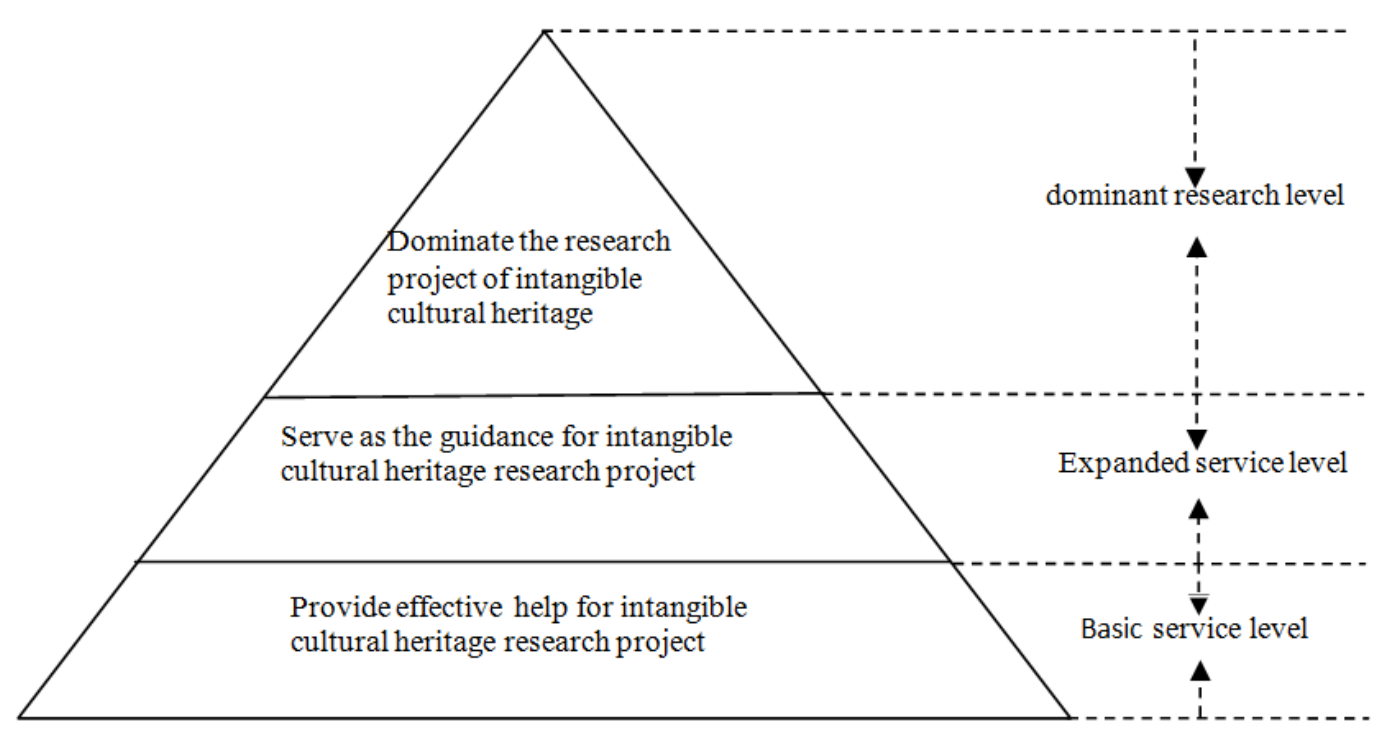

Figure 2. Hierarchical graph of the university library's participation in the cultural heritage research project

To see it specifically: (1) in the basic service level, university libraries use its own advantage of collecting, processing and sorting the scientific research information as it is the important information service institute in colleges and universities, to provide corresponding literature, research information, and services such as excavation, finishing and consulting for university teachers and the relevant experts and scholars that engaged in intangible culture heritage research, and to provide effective help for the relevant research projects [6]; (2) in the expanded service level, the university library can serve as the guidance for intangible cultural heritage research project. On the one hand, the university library can make full use of its own system resources and closely combine with the local demands of intangible cultural heritage protection work, to establish the research topics and to organize the relevant experts and scholars so as to conduct the research activities, providing theoretical and practical basis for the sorting, protection, inheritance, utilization, research and development work of the intangible cultural heritage. On the other hand, the university library should also create conditions to encourage experts and scholars to carry out special investigation on the intangible cultural heritage with local characteristics, so as to guide for the local intangible cultural heritage protection. In this way, it can not only expand the research strength of intangible cultural heritage, but also improve the academic research ability of library staff [7]; (3) in the dominant research level, the related professional librarians in university library can properly apply for some research topics related to intangible cultural heritage according to their own situation. Presently, most of the librarians recruited in domestic universities are required to have a master's degree, and the academic level of university library staff is increasing year by year. When recruiting librarian, the university libraries are likely to enroll those with doctoral and master's degree based on their discipline and major background [8], and the academic structure of will also be dominated by the master's and doctoral librarians. Therefore, the university library will be endowed with talents condition dominating the research project of intangible cultural heritage in the near future. The above content is the level classification for university library participating in intangible cultural heritage research; libraries can select specific levels according to their own conditions. 


\section{Conclusions}

From the above analysis, we believe that the essence for China's university libraries to participate in the protection of intangible cultural heritage is the inherent requirement for carrying forward the excellent traditional culture. From the perspective of the protection method, providing the paper document and constructing network protection platform forms the basic way for college and universities to protect the intangible culture heritage; providing publicity service expands the audience of intangible cultural heritage protection, increased people's cognition and identification degree; participating in research projects elevates the university library's protection level, provides the way for dynamic development of the intangible cultural heritage.

\section{References}

[1] Jing Huang. Local Academic Libraries and Inheritance Protection of Intangible Cultural Heritage -- A Case of the Huangmei Operain Anqing City, Journal of Academic Library and Information Science, 2012 (2)23-25, 45.

[2] Yun Feng, Yu-lin Yang and Fan-xiu Kong. The construction of characteristic collection of National University Library under the perspective of the protection of intangible cultural heritage, New Century Library, 2013(10)52-55.

[3] Yan Li. Thoughts on the Participation of the University Library in the Protection of Intangible Cultural Heritage, The Journal of the Library Science in JiangXi, 2009(3) 82-83.

[4] Hui-lian Hu. The Advantages and Measures for University Library to Participate in the Protection of Intangible Cultural Heritage, Big Stage, 2012(6)287-288.

[5] Wei-guo Shi. On the Definition and Function of Research Libraries, The Journal of the Library Science in Jiangsu, 2002(6)43-46.

[6] Zhi-hong She. The protection measures of University Library in the Intangible cultural heritage, Library Work and Study, 2009(10) 80-82.

[7] Yan-xing Kang. On the Function of Libraries' Safeguarding the Intangible Cultural Heritage, Library Development, 2005(6)19-21.

[8] Han-hua Wu, Fang Zhang. The Current Status of Human Resources in Chinese Academic library, Journal of Academic Libraries, 2015(3)43-50. 